\title{
GARCINIA KOLA HECKEL SEEDS DORMANCY-BREAKING
}

\author{
O. EYOG-MATIG ${ }^{1} *$ - A.K.N. AOUDJI ${ }^{1}-$ C. LINSOUSSI $^{2}$ \\ ${ }^{I}$ Sub-Saharan Africa Forest Genetic Resource Programme, International Plant Genetic \\ Resource Institute for West and Central Africa, 08BP: 0932 Cotonou, Benin \\ ${ }^{2}$ Département d'Aménagement et Gestion de l'Environnement, Faculté des Sciences \\ Agronomiques Université d'Abomey-Calavi, BP 526 Cotonou \\ e-mail:o.eyog-matig@cgiar.org \\ (Received $31^{\text {th }}$ Jan 2006 ; accepted $13^{\text {th }}$ March 2007)
}

\begin{abstract}
Seeds dormancy-breaking was investigated for Garcinia kola Heckel by using techniques that can afford small farmers for domestication. Garcinia kola seeds in their natural habitat have 6 weeks to 18 months dormancy. The methods experimented to overcome seed dormancy included conservation or removal of seed coat followed by pre-germination treatments including soaking for 24 hours in cold water $\left(25^{\circ} \mathrm{C}\right)$, or in hot water $\left(70^{\circ} \mathrm{C}\right)$; immersion in pineapple juice or incorporation in banana false trunk for one week. Sand mixed with compost and sawdust were used as germination substrata. The germination rates were quite low $(0-40 \%)$ due to poor seed quality. Seed coat removal followed by soaking in cold water affected positively dormancy-breaking while the warm treatment caused embryo destruction and failure of seed germination. The effective dormancy-breaking methods to be recommended were decoated seeds soaked in cold water, coated seeds placed in banana false trunk and coated seeds soaked in pineapple juice where germination started 95, 102 and 110 days respectively from sowing with 130-141 days as mean germination time. The germination substratum irrespective of dormancy-breaking method didn't affect significantly either the germination percentage or the germination time. Further investigation is necessary to improve dormancy-breaking.
\end{abstract}

Keywords. Garcinia kola, seed dormancy-breaking, germination rate, germination time, seedling growth.

\section{Introduction}

Garcinia is a tropical plant genus including several species in Africa, America and Asia. These species are commonly useful for many purposes [12]. Garcinia kola Heckel is a highly valued and multi-purpose tree for its fruits, seeds, stems, roots and barks that are used in Western and Central African regions. Garcinia kola's interest is proved as one of the many non-timber forest products that are of high socio-economic importance [1]. It occupies the third rank of medicinal plants in Benin in terms of number of recipes in which the species is incorporated [14] and investigations proved that Garcinia kola seeds contain compounds useful in curing several diseases $[4,6]$.

Because of its high interest resulting in its overexploitation, Garcinia kola is extinction-threatened in several West and Central African countries such as Ivory Coast [5], Togo [8], Congo and Cameroon [15]. Considering its importance and to prevent genetic erosion, appropriate strategies should be developed to promote its sustainable use. It is therefore useful to undertake on farm conservation by small farmers through agroforestry systems. This will decrease the pressure on wild individuals. However such methods require an accurate knowledge of its propagation.

The major difficulty in Garcinia kola propagation as for several species of Garcinia genus is related to seeds germination. Due to dormancy, Garcinia kola seeds can take 
18 months to germinate [2]. It is therefore necessary to find out adequate solutions to overcome seed dormancy.

Previous studies investigated on Garcinia kola Heckel and Garcinia cowa Roxb. seeds germination [7, 11]. Both studies were carried out in laboratory conditions and part of the outcomes couldn't be implemented by small farmers. There was therefore need to develop new techniques. The present study was carried out to partially fill this gap of knowledge. It aimed at improving seed germination by using techniques that can afford small farmers.

\section{Materials and methods}

\section{Studied material: Garcinia kola Heckel}

Garcinia kola Heckel (Guttiferae) commonly occurs in humid lowland rainforests or gallery forests of West and Central African sub-regions. Its geographical distribution area (Fig. 1) extends from Congo to Sierra Leone [16].

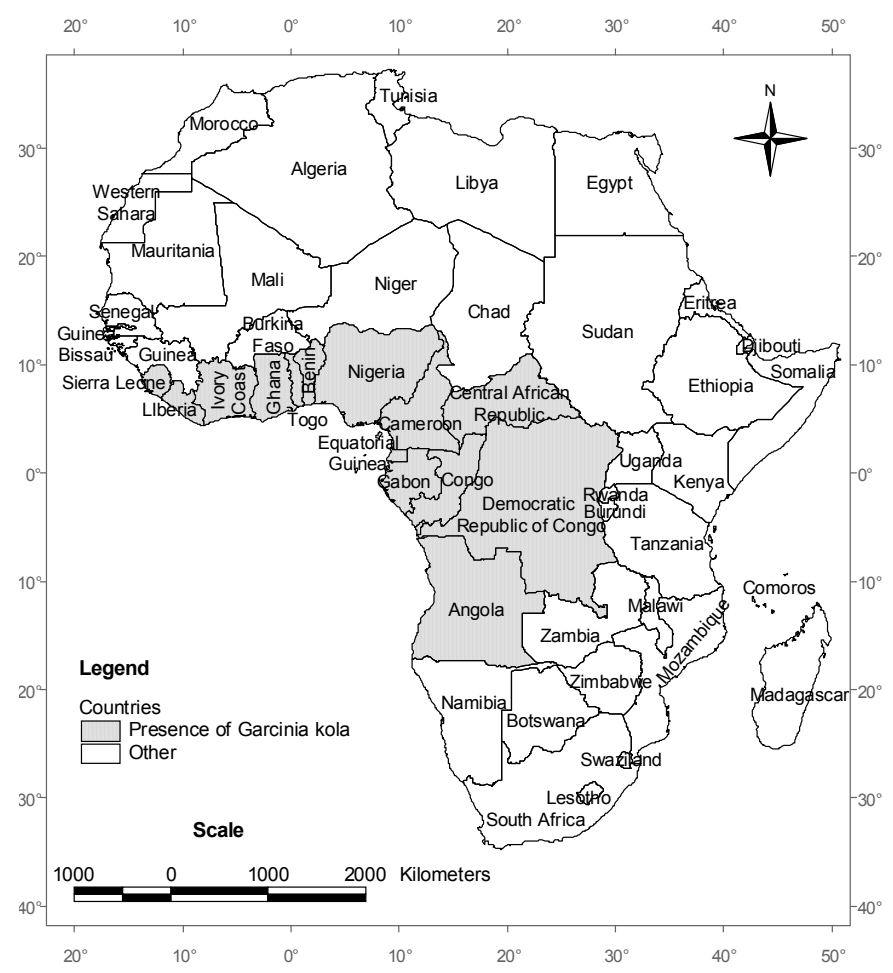

Figure 1. Garcinia kola geographical distribution

It grows in coastal areas and lowland plains up to $300 \mathrm{~m}$ above sea level with average water availability equivalent to $2,000-2,500 \mathrm{~mm}$ of rainfall per annum. Temperature in theses regions ranges from $32.15^{\circ} \mathrm{C}$ to $21.4^{\circ} \mathrm{C}$ with a minimum relative humidity of $76.34 \%$ [10].

Garcinia kola is a medium-sized and shade-tolerant tree with a cylindrical trunk that is slightly buttressed to the ground. The tree has a dense crown which is compact, but not spreading. Male and female flowers are separate. Fruits are smooth, reddish yellow; seed coat is brown with branched lines. The fruits usually fall to the ground where animals feed on them and disperse the seeds. 
Two types of seeds were used: fresh and dried seeds. The sample was homogenized by mixing the two categories before starting the experiment.

\section{Study of dormancy-breaking}

The treatments tested were selected based on firstly the information published in scientific papers [11] and secondly non-published information provided by scientists. Dormancy-breaking techniques combined seed coat treatment and pre-germination treatment. Seed coat treatment included seeds with and without seed coat. Then seed coat treatments were matched with pre-germination treatments including: (i) seeds soaking for 24 hours in water at ambient temperature (about $25^{\circ} \mathrm{C}$ : cold water); (ii) seeds soaking for 24 hours in hot water previously boiled at $70^{\circ} \mathrm{C}$; (iii) seeds soaking for one week in pineapple juice; (iv) seeds incorporation for one week within banana false trunk; except decoated seeds in pineapple juice and within banana false trunk (Table 1). These two treatments were not used because not significantly different from coated seeds according to non-published information.

Table 1. Factors and treatments description

\begin{tabular}{ccc}
\hline Treatment number & Seed coat treatment & Dormancy-breaking method \\
\hline 1 & Decoated seeds & Cold water $\left(30^{\circ} \mathrm{C}\right)^{1}$ \\
2 & Decoated seeds & Boiled water $\left(70^{\circ} \mathrm{C}\right)^{1}$ \\
3 & Coated seeds & Cold water $\left(30^{\circ} \mathrm{C}\right)^{1}$ \\
4 & Coated seeds & Boiled water $\left(70^{\circ} \mathrm{C}\right)^{1}$ \\
5 & Coated seeds & Pineapple juice ${ }^{2}$ \\
6 & Coated seeds & Banana false trunk \\
\hline
\end{tabular}

${ }^{I}$ Duration of the pre-treatment $=24$ hours

${ }^{2}$ Duration of the pre-treatment $=$ one week

Two substrata were used in nursery: sand mixed with compost and sawdust. Polyethylene containers were filled in with substratum. The containers had $8 \mathrm{~cm}$ diameter, $23 \mathrm{~cm}$ height with two rows of small holes ( $3 \mathrm{~mm}$ diameter) for drainage; the first row of holes was situated at $3 \mathrm{~cm}$ above the bottom and the second at $7 \mathrm{~cm}$.

One seed was sown per container. The number of replications per dormancybreaking treatment and substratum was 25 seeds/containers or a total of 300 containers for the whole experiment. Containers were watered on a daily basis and saturated with water.

Observations were made on a daily basis and the seed germination date was recorded for each container. The germination date was confounded with seed levee date. The experiment was stopped when no new germinated seed occurred for a consecutive 20 days period. The germination rate and the mean germination time were calculated.

Germination rate (\%): $G R i=\left(n_{i} / N\right) \times 100$; where $G R i$ is the germination rate of the treatment $i ; n_{i}$ is the number of germinated seeds of the treatment $i$ and $N$ is the total number of seeds.

Mean germination time (days): $M G T i=\sum(t j \times n i j) / n i$; where $M G T i$ is the mean germination time of the treatment $i$; $t_{j}$ is the $j^{\text {th }}$ day from sowing; $n_{i j}$ is the number of germinated seeds of the treatment $i$ at the is the $j^{\text {th }}$ day from sowing and $n_{i}$ is the total number of germinated seeds of the treatment $i$. 
Germination trends over time were analyzed. Germination counts were analyzed with Chi square test; germination times were compared with analysis of variance completed by Newman-Keuls mean comparison test. Minitab software was used to perform statistical analyses.

\section{Results}

\section{Germination start}

Germination occurred (Table 2) from sowing after 95 days for decoated seeds soaked in cold water, 102 days for coated seeds placed within banana false trunk, 110 days for coated seeds soaked in pineapple juice and 153 days for coated seeds soaked in cold and hot water. Decoated seeds maintained in hot water failed to germinate.

Table 2. Germination start

\begin{tabular}{lc}
\hline Dormancy-breaking methods & First germination (days) \\
\hline Decoated seeds in cold water & 95 \\
Coated seeds in banana trunk & 102 \\
Coated seeds in pineapple juice & 110 \\
Coated seeds in cold water & 153 \\
Coated seeds in hot water & 153 \\
Decoated seeds in hot water & - \\
\hline
\end{tabular}

\section{Germination spread over time}

Germination trend analysis (Fig. 2) revealed germination spread over time. Coated seeds incorporated in banana false trunk showed several stages of synchronous germination. Similar trend was observed for coated seeds soaked in cold water. Coated seeds soaked in pineapple juice showed synchronous germination at the beginning (110th day) followed by regular germination occurrence until the 180th day. Germination occurrence was irregular for decoated seeds soaked in cold water and coated seeds soaked in hot water showing no clear synchronous germination. 


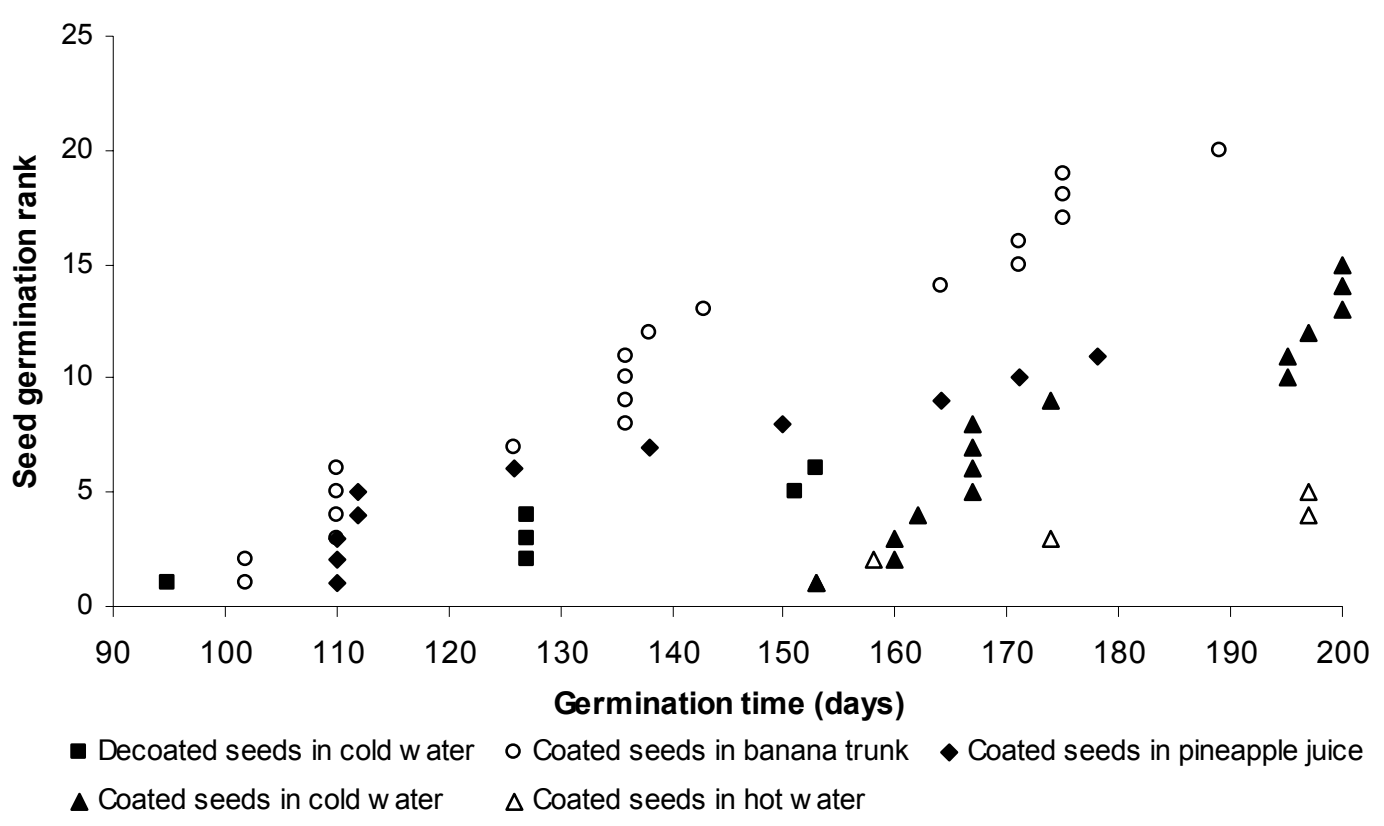

Figure 2. Seeds germination over time

\section{Germination rate}

Seed germination varied significantly according to dormancy-breaking methods (table 3). Except decoated seeds soaked in hot water where germination failed, the germination percentage (Table 3) ranged from 10\% (coated seeds soaked in hot water) to $40 \%$ (coated seeds placed in banana false trunk). Dormancy-breaking treatments could be ranged in four levels of effectiveness according to germination percentage. The first level was for coated seeds placed in banana false trunk (40\%); the second was for coated seeds soaked in cold $(30 \%)$; the third germination level was that of coated seeds soaked in pineapple juice (24\%) and the last level included decoated seeds soaked in cold water and coated seeds soaked in hot water (10-12\%).

Table 3. Seed germination

Chi square test on seed germination: Chi square value $=17.645 ; P=0.001$

\begin{tabular}{lccc}
\hline \multirow{2}{*}{ Dormancy-breaking methods } & \multicolumn{2}{c}{ Seed germination (counts) } & Germ. rate \\
\cline { 2 - 3 } & Non germ. seeds & Germ. seeds & $(\%)$ \\
\hline Coated seeds in banana trunk & 30 & 20 & $40 \pm 11.31$ \\
Coated seeds in cold water & 35 & 15 & $30 \pm 8.49$ \\
Coated seeds in pineapple juice & 38 & 12 & $24 \pm 0.00$ \\
Decoated seeds in cold water & 44 & 6 & $12 \pm 11.31$ \\
Coated seeds in hot water & 45 & 5 & $10 \pm 8.49$ \\
\hline
\end{tabular}

The assessment of substratum effect revealed that sand mixed with compost or sawdust irrespective of dormancy-breaking methods didn't affect significantly seed germination $($ Chi square $=0.541 ; \mathrm{P}=0.462)$. 


\section{Germination time}

The mean germination time (Table 4) varied significantly according to dormancybreaking methods $(\mathrm{P}=0.000)$. The mean germination time was lower for decoated seeds in cold water, coated seeds in pineapple juice and coated seeds in banana false trunk (130-141 days) than for coated seeds in cold water and in hot water (176-178 days).

Table 4. Mean germination time

\begin{tabular}{lc}
\hline Dormancy-breaking methods & Mean germination time (days) \\
\hline Decoated seeds in cold water & $130 \mathrm{a}$ \\
Coated seeds within banana trunk & $141 \mathrm{a}$ \\
Coated seeds in pineapple juice & $135 \mathrm{a}$ \\
Coated seeds in cold water & $176 \mathrm{~b}$ \\
Coated seeds in hot water & $178 \mathrm{~b}$ \\
\hline *Treatments followed by the same letters are not significantly different.
\end{tabular}

*Treatments followed by the same letters are not significantly different.

The assessment of substratum effect revealed that sand mixed with compost or sawdust irrespective of dormancy-breaking methods didn't affect significantly the germination time $(\mathrm{P}=0.99)$.

\section{Discussion}

The analysis of germination trends showed spreading over time. The spreading of seed germination was reported to be due to variability in dormancy depth [3]. Basic pattern with respect to temporal distribution were distinguished [13]: quasisimultaneous, when germination of all the seeds occurs over a relative brief period; intermittent, irregular germination over long time periods, showing essentially multi modal distribution; continuous, in which members of the population germinate over an extended time period, with no clear peaks and periodic germination, which is multi modal but shows more regular periodicity. Garcinia kola seeds germination in the trial can be classified as periodic.

The germination rates were quite low $(0-40 \%)$. The failure of seeds germination may be due to embryo death or deep seed dormancy. The test of ungerminated seeds viability is usually performed by using tetrazolium chloride [7, 9]. The high proportion of ungerminated seeds may be a consequence of a high proportion of dead seeds; however the non-implementation of the tetrazolium chloride test limits this hypothesis.

Germination spreading and poor seed quality may be correlated to seed moisture content. Garcinia kola seeds are sensitive to desiccation that usually decreases seed viability. It was revealed that the germination rate decreased with the seed moisture content and at 20.2\% moisture content every seeds died and failed to germinate; the seed water content at harvest $(50.4 \%)$ allowed the best germination rate and the shortest spreading out of the germination period [11]. Comparable results were obtained for Garcinia cowa, a tropical recalcitrant seed. Below $40 \%$ of moisture content, seeds viability decreased rapidly and all seeds died at approximately $17 \%$ of moisture content [7]. Dried seeds used in the experiment were responsible of poor seed germination and germination spread. Further investigation will enable to assess more accurately how seed viability and dormancy depth vary according to the seed moisture content to determine the suitable seeds storage conditions. 
Decoated seeds soaked in hot water $\left(70^{\circ} \mathrm{C}\right)$ failed to germinate due to embryos destruction by the warm treatment. Germination failure was previously reported when soaking Garcinia kola seeds in warm water $\left(60^{\circ} \mathrm{C}\right)$ for 8 hours [11] and this confirm that the warm water treatment affected negatively Garcinia kola seeds germination. Coated seeds in hot water could germinate showing that seed coat may protect in certain extent embryo from destruction by warm.

Germination started early for decoated seeds in cold water (95 days) while for coated seeds in cold water it occurred 58 days later. The mean germination time was therefore significantly lower for decoated seeds soaked in cold water (130 days) than for coated seeds soaked in cold water (176 days). Seed coat removal therefore affected positively dormancy-breaking by reducing the mean germination time of 46 days. Comparable result was obtained for Garcinia cowa seeds where the total removal of seed coat was revealed as the most effective dormancy-breaking treatment [7]. Germination occurred also quite early for coated seeds placed in banana false trunk and coated seeds soaked in pineapple juice.

The effectiveness of seed coat removal treatment enabled to assume that part of seed dormancy mechanism is external or coat-imposed. The effectiveness of the pineapple juice and the banana trunk treatments may be due to the presence of some compounds that reduce the dormancy-induction properties in the seeds. The hypothesis of embryo dormancy on Garcinia kola seeds was reported basing on the presence of substance associated with germination inhibition such as phenol in the seeds [11]. In this case decoated seeds soaking in cold water may decrease the content of such compounds and promote seed germination. The same mechanism may explain the effectiveness of pineapple juice and banana trunk treatment.

Basing on the germination time, as the germination percentage was affected by poor seed quality, the effective dormancy-breaking treatments to be recommended for propagation by small farmers are decoated seeds soaked in cold water, coated seeds in banana false trunk and coated seeds in pineapple juice. Nevertheless, these methods are less efficient when compared with previous study having reported mean germination time of 26-72 days [11]. The difference may derive from the fact that these authors worked in seed tray with laboratory conditions while our study was carried out in nursery where environmental conditions are subjected to less control. Moreover the germination date was not determined accurately and confounded to the levee date and until 10 days may separate germination from seed levee. The seed tray step stage may improve G. kola seed germination. However, the efficiency of the treatments implemented may be improved to shorten the germination time and increase the germination percentage. To this end, the understanding of dormancy mechanism will be necessary basing on natural processes; for instance to investigate whether seeds ingestion by elephants and other animals affected in certain extent dormancy-breaking.

In the appraisal of substratum effect, sand mixed with compost or sawdust didn't significantly affect either the germination occurrence or the germination time. The reason is that water availability for seed germination was enough in both substrata. The role of substratum is to provide favorable environment especially moisture and air required for seed germination. In the experiment water was artificially provided and containers were saturated daily so that even seeds germinating in substratum with low water-holding capacity were not disadvantaged. 


\section{Conclusion}

Garcinia kola seeds had poor germination due to dormancy and poor seed quality. Seed viability is affected by desiccation. The germination rate was $0-40 \%$ and the mean germination time 130-178 days. Dormancy-breaking was improved by seed coat removal followed by soaking in cold water $\left(25^{\circ} \mathrm{C}\right)$. Germination was affected negatively by soaking decoated seed in warm water where seeds failed to germinate. The most effective treatments to overcome seed dormancy were seed coat removal followed by soaking in cold water for 24 hours in cold water and seed incorporation within banana false trunk or immersion in pineapple juice for one week. The efficiency of these treatments may be improved.

\section{REFERENCES}

[1] Adebisi, A.A. (2004): A case study of Garcinia kola nut production-toconsumption system in J4 area of Omo forest reserve, South-west Nigeria. - In: Sunderland, T. and Ndoye, O. (eds): Forest Products, Livelihood and Conservation (Case study of Non-Timber Forest Product Systems), Volume 2 Africa, pp. 115-132.

[2] Aduse-Poku, K. Nyinaku, F., Atiase, V. Y., Awuah, R., Mensah, E. O., Nyantakyi, D., Owusu, H. K. \& Agyenim-Boateng, B. (2003): Improving rural livelihoods within the context of sustainable development: case study of Goaso forest district. Tropenbos International Ghana, University of Amsterdam \& Institute of Renewable Natural Resources, $50 \mathrm{pp}$.

[3] Bewlyey, J.D. (1982): Viability, Dormancy and Environmental Control. - In: Physiology and Biochemistry of Seed, pp. 62-65.

[4] Esimone, C.O., Nwafor, S.V., Okoli, C.O., Chah, K.F., Uzuegbu, D.B., Chibundu, C., Eche, M.A. \& Adikwu, M.U. (2002): In vivo evaluation of interaction between aqueous seed extract of Garcinia kola Heckel and ciprofloxacin hydrochloride. - American Journal of Therapeutics 9(4): 275-280.

[5] FAO (1996): Côte d'Ivoire: Rapport de pays pour la conférence technique internationale de la FAO sur les ressources phytogénétiques. FAO, 75 pp.

[6] Farombi, E.O., Adepoju, B.F., Ola-Davies, O.E. \& Emerole, G.O. (2005): Chemoprevention of aflatoxin B1-induced genotoxicity and hepatic oxidative damage in rats by kolaviron, a natural biflavonoid of Garcinia kola seeds. European Journal of Cancer Prevention 14(3): 207-214.

[7] Liu, Y., Qiu, Y-P., Zhang, L. \& Chen, J. (2005): Dormancy Breaking and Storage Behavior of Garcinia cowa Roxb. (Guttiferae) Seeds: implications for Ecological Function and Germplasm Conservation. - Journal of Integrated Plant Biology 47(1): 38-49.

[8] Ministère de l'Environnement et des Ressources Forestières de la République du Togo (1998): Rapport National sur la Biodiversité: Version provisoire. Lomé, $69 \mathrm{pp}$.

[9] Nasreen, S., Yousaf, M., Mohmand, A.S. \& Ashraf Mailk, M. (2002): Study of Seed Dormancy Mechanisms; Causes and Control. - Asian Journal of Plant Sciences 1(2): 210-212. 
[10] Ntamag, C.N. (1997): Spatial distribution of non-timber forest production collection: a case study of south Cameroon. - M.sc. Thesis, Wageningen Agricultural University, Department of Forestry, The Netherlands, $76 \mathrm{pp}$.

[11] Nzegbule, E. \& Mbakwe, R. (2001): Effect of pre-sowing and incubation treatment on germination of Garcinia kola (Heckel) seeds. - Fruits 56(6): 437442.

[12] Rai, N.D. (2003): Human use, reproductive ecology and life history of Garcinia gummi-gatha a Non Timber Forest Product, in the western Gaths, India. - Thesis submitted in partial fulfillment of the Requirements for the Degree of Doctor of Philosophy. Pennsylvania State University, Graduate School, Department of Biology, $191 \mathrm{pp}$.

[13] Salisbury, E. (1961): - Weeds and Aliens. Collins, London, UK, 384 pp.

[14] Souza de, S. (2001): Rapport du Bénin. - In Eyog-Matig, O., Adjanonhoun, E., Souza de, S. \& Sinsin, B. (eds): Compte rendu de la première réunion du Réseau "Espèces Ligneuses Médicinales" 15-17 décembre 1999 Station IITA Cotonou, Bénin. International Plant Genetic Resources Institute, Kenya, Nairobi, pp. 4-10.

[15] Tchatat, M. (1999): Produits forestiers autres que le bois d'œuvre (PFAB): place dans l'aménagement durable des forêts denses humides d'Afrique centrale. Série FORAFRI, document 18. CIRAD, CIFOR, IRAD \& CARPE, 103 pp.

[16] Vivien, J. \& Faure, J.J. (1985): Arbres des forêts denses d'Afrique Central. Ministère des Relations Extérieures, Coopération et Développement et Agence de Coopération Culturelle et Technique. Paris, pp. 214-215. 